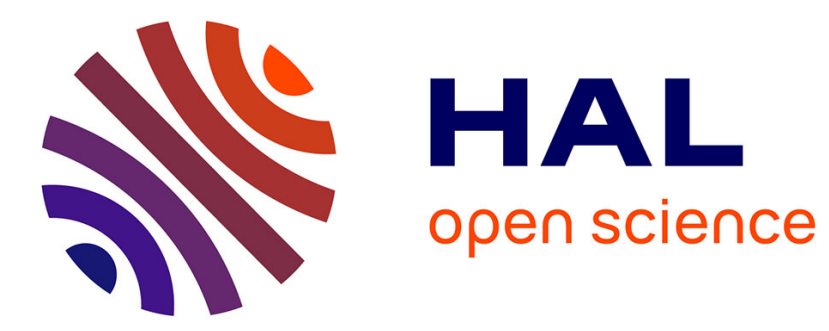

\title{
Effect of boron segregation on bainite nucleation during isothermal transformation
}

P Douguet, G da Rosa, P Maugis, J Drillet, K Hoummada

\section{To cite this version:}

P Douguet, G da Rosa, P Maugis, J Drillet, K Hoummada. Effect of boron segregation on bainite nucleation during isothermal transformation. Scripta Materialia, 2022, 207, pp.114286. 10.1016/j.scriptamat.2021.114286 . hal-03351339

\section{HAL Id: hal-03351339 \\ https://hal.science/hal-03351339}

Submitted on 22 Sep 2021

HAL is a multi-disciplinary open access archive for the deposit and dissemination of scientific research documents, whether they are published or not. The documents may come from teaching and research institutions in France or abroad, or from public or private research centers.
L'archive ouverte pluridisciplinaire HAL, est destinée au dépôt et à la diffusion de documents scientifiques de niveau recherche, publiés ou non, émanant des établissements d'enseignement et de recherche français ou étrangers, des laboratoires publics ou privés. 


\title{
Effect of boron segregation on bainite nucleation during isothermal transformation
}

\author{
P. Douguet ${ }^{1,2}$, G. Da Rosa ${ }^{2}$, P. Maugis ${ }^{1 *}$, J. Drillet ${ }^{2}$ and K. Hoummada ${ }^{1}$ \\ ${ }^{1}$ Aix Marseille University, CNRS, IM2NP, Marseille, France \\ ${ }^{2}$ ArcelorMittal Maizières Research SA, Voie Romaine, BP30320, 57283 Maizières les Metz, France \\ *Corresponding author, philippe.maugis@im2np.fr
}

\section{Keywords}

Grain boundary segregation; phase transformation kinetics; atom probe tomography; advanced highstrength steels; bainitic steels

\begin{abstract}
The effects of boron segregation and austenite grain size on the bainitic isothermal transformation of a high-strength steel were studied independently. Dilatometry, microstructural observations and previous atom probe tomography analyses showed that bainitic transformation rate decreases with increasing boron excess at austenite grain boundaries. We also found that boron segregation causes an unexpected grain size effect: large austenite grains transform faster than small ones. A kinetic model assuming slow nucleation at austenite triple junctions and rapid growth of bainitic nuclei successfully described our experimental data. These results confirm that bainite nucleation is inhibited by segregated boron at grain boundaries. On this basis, austenitic grain size could be optimized to make the most of boron addition in advanced high-strength steels.
\end{abstract}

\section{Main body}

Boron has been added to steels for decades to improve their hardenability [1-4] and delay the ferritic and bainitic transformations [5]. Only few tens of ppm of boron are effective to slow down significantly the transformation kinetics, with an optimum between $5 \mathrm{ppm}$ [6,7] and $30 \mathrm{ppm}$ [1]. This effect is usually ascribed to the inhibition of nucleation sites on austenite grain boundaries by boron segregation $[9,10]$. A frequent assumption is that boron decreases the austenitic grain boundary energy and thus reduces the ferritic and bainitic nucleation barriers [9].

The effects of boron segregation on the bainitic isothermal transformation kinetics were investigated in numerous studies [10-14]. If a delay is always observed, its magnitude varies with heat cycles and chemistry. Some studies report a smaller effect [11-13] than others [10,14,15]. Zhu [14] reported that the microstructure is strongly impacted by the addition of boron and by the decrease in nucleation rate, detailing that a smaller number of larger bainite packets are formed. Song [15] observed that boron limits nucleation at austenitic grain boundaries. Thus, a smaller number of bainite crystallographic variants were observed within prior austenitic grains.

Austenitic grain size was not considered in these studies as austenite was always homogenized at a high soaking temperature above $1000^{\circ} \mathrm{C}$ prior to experiments. The most common grain size effect on isothermal kinetics is a decrease in the transformation rate with increasing grain size $[16,17]$. The classical JMAK equation models this kind of behavior [18-20]. However, conflicting grain size effects were observed in various steels and experimental conditions. Matsuzaki and Bhadeshia [21] elaborated an alternate model to rationalize these behaviors: according to their model, the effect of austenitic grain size depends on nucleation rate and growth rate of bainite. For very low nucleation rate on grain 
boundaries compared to growth rate, larger grains accelerate the bainitic transformation. The opposite effect occurs when the rate balance is reversed. The interactions between boron effect and austenitic grain size effect on nucleation rate and growth rate need to be clarified in order to understand the experimental disparities in the literature.

The aim of this study is to highlight the local inhibition of bainite nucleation by boron segregation and to explain how it affects the bainitic isothermal transformation kinetics. To this end, boron segregation and austenitic grain size were controlled independently, and their respective effects were discerned. A model was designed to support the experimental results.

The chemical composition of the studied steel is Fe-0.075C-2.5Mn-0.0030B-0.02Ti in wt.\% or Fe$0.34 \mathrm{C}-2.45 \mathrm{Mn}-0.0150 \mathrm{~B}-0.03 \mathrm{Ti}$ in at.\%. Ti was added to protect $\mathrm{B}$ from precipitating with $\mathrm{N}$ [22]. Experiments were also performed on a boron-free alloy. The alloys are labelled respectively $30 \mathrm{~B}$ and 0B from their boron content. After casting, the material was hot-rolled, then cooled at $30^{\circ} \mathrm{C} / \mathrm{h}$ from $460^{\circ} \mathrm{C}$ to room temperature and finally cold-rolled to $1.3 \mathrm{~mm}$ thick sheets.

Boron segregation is nowadays investigated with atom probe tomography (APT) [23-27]. This technique is used to measure the boron atomic excess $\Gamma$ (in at.nm ${ }^{-2}$ ) on prior austenitic grain boundaries $(\gamma \mathrm{GBs})$. Da Rosa et al. [24] demonstrated that boron excess can be controlled by varying the austenitizing temperature: APT measures after quenching to room temperature showed that boron excess increases with the soaking temperature. Indeed, at higher temperatures, boron-containing precipitates dissolve. The resulting increase in solute boron compensates for the lower segregation ratio.

The heat treatments shown in Fig. 1 were performed. They are composed of three stages, enabling to control independently the austenite grain size and the amount of segregated boron. The first soaking stage controls the austenitic grain size. For temperature $\mathrm{T}_{\mathrm{GS}}$ of $820^{\circ} \mathrm{C}, 900^{\circ} \mathrm{C}$ and $1100^{\circ} \mathrm{C}$, three distinct sizes were obtained: $8 \mu \mathrm{m}, 12 \mu \mathrm{m}$ and $50 \mu \mathrm{m}$. Austenite grain size was measured after a heat cycle interrupted by a quench at the end of the first soaking stage. At a constant heating rate of $5^{\circ} \mathrm{C} . \mathrm{s}^{-1}, \mathrm{Ac} 3$ was measured around $870^{\circ} \mathrm{C}$. Despite the $820^{\circ} \mathrm{C}$ lowest maximum temperature, $600 \mathrm{~s}$ of holding were enough to complete the austenitic transformation and no untransformed ferrite was observed after soaking. The second-stage temperature controls the boron excess on $\gamma$ GBs. Samples were held at temperatures $\mathrm{T}_{\Gamma}$ ranging from $820^{\circ} \mathrm{C}$ to $900^{\circ} \mathrm{C}$ as shown in Figs $1 \mathrm{a}$ and $1 \mathrm{~b}$ (blue and red paths). For two samples, $\mathrm{T}_{\mathrm{GS}}=\mathrm{T}_{\Gamma}$ and only one stage is required (Fig.1b green path and Fig.1c). After $120 \mathrm{~s}$ holding, it was found that boron segregation had reached an equilibrium stationary value [24, 27]. Samples were then cooled at $500^{\circ} \mathrm{C} / \mathrm{s}$ to the isothermal bainitic transformation temperature of $460^{\circ} \mathrm{C}$.

Due to the difficulty to observe enough prior $\gamma \mathrm{GBs}$ with APT, boron excess in this study was not measured, but computed using the kinetic model described in ref. [24]. This model involves a diffusion coefficient of boron fitted to $\mathrm{D}_{0}=8 \times 10^{-8} \mathrm{~m}^{2} \cdot \mathrm{s}^{-1}$ and $\mathrm{Q}=0.83 \mathrm{eV}$, and a segregation enthalpy of boron $\mathrm{H}_{\text {seg }}=-0.39 \mathrm{eV}$. Boron excess at the beginning of the $460^{\circ} \mathrm{C}$ isotherm is assumed to depend only on the second-stage temperature and on the cooling rate. Possible diffusion of boron at $460^{\circ} \mathrm{C}$ is neglected. The boron excess values were then calculated for a quench at $500^{\circ} \mathrm{C} / \mathrm{s}$ stopped at $460^{\circ} \mathrm{C}$. Just as the experimental values, computed boron excess increases with the soaking temperature. For temperatures $\mathrm{T}_{\Gamma}$ of $820^{\circ} \mathrm{C}, 860^{\circ} \mathrm{C}$ and $900^{\circ} \mathrm{C}$, the excesses are respectively $\Gamma=2.4,3.0$ and 3.7 at.nm ${ }^{-2}$. For details about the APT measurements and the calculations, the reader is referred to refs. [24], [26] and [27].
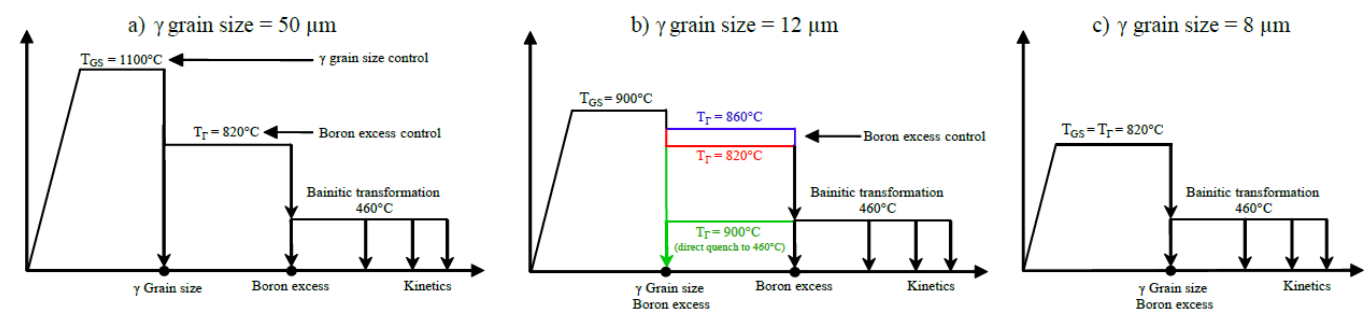
Figure 1. Heat patterns performed on our samples to obtain three different $\gamma$ grain sizes with varying boron excesses. a) $50 \mu \mathrm{m}$. b) $12 \mu \mathrm{m}$. c) $8 \mu \mathrm{m}$.

Heat treatments and dilatometric curves of the bainitic transformation were obtained with a Bähr DIL805 dilatometer. Electron backscatter diffraction (EBSD) acquisitions were obtained with a JEOL 7001F microscope. Average austenitic grain sizes were measured by the intercept method after BechetBeaujard etching. Microstructures, phase fractions and average bainite island sizes were observed by optical microscopy after picral and metabisulfite etching.
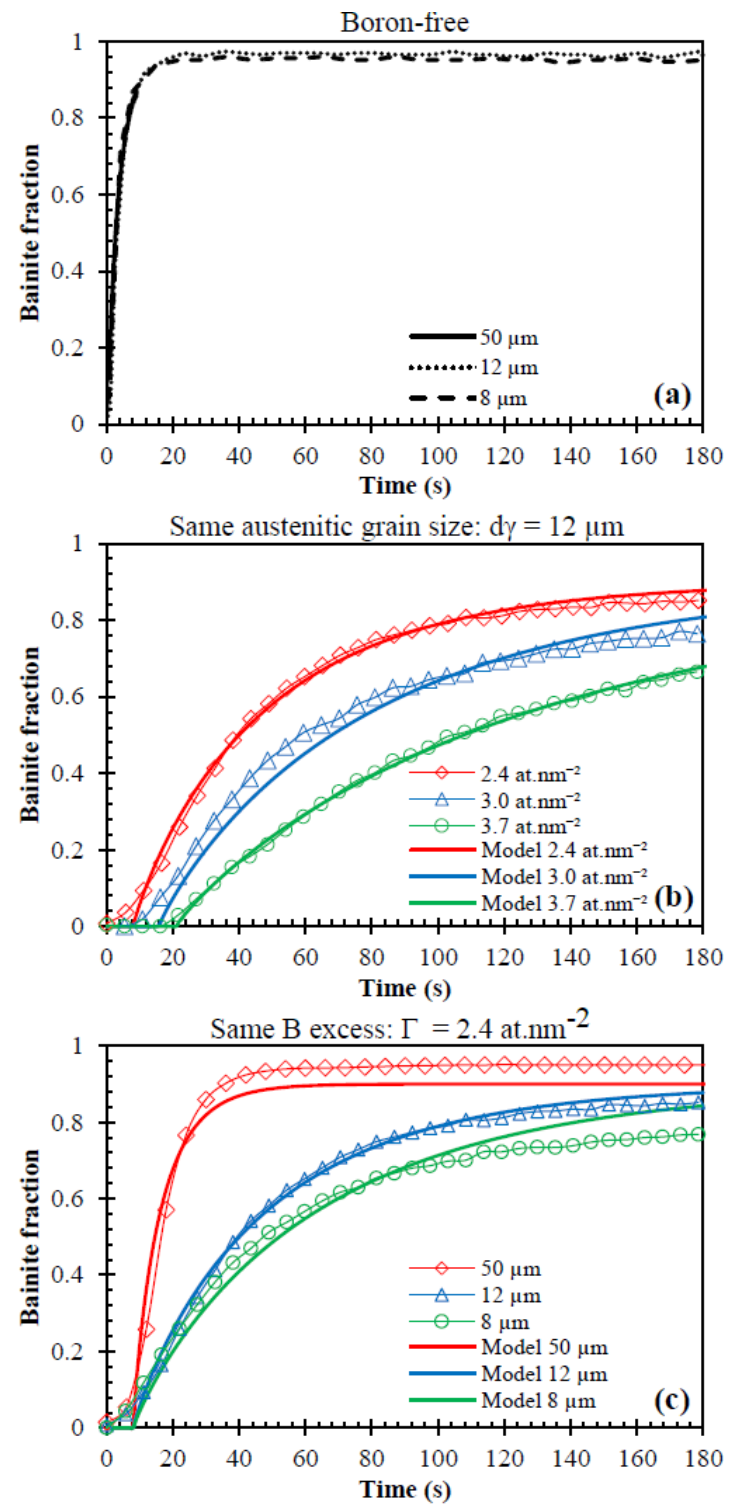

Figure 2. Kinetics of bainitic transformation. a) Effect of grain size in boron-free steel. b) Effect of boron excess for a fixed austenitic grain size of $12 \mu \mathrm{m}$. c) Effect of austenitic grain size for a fixed boron excess of 2.4 at.nm ${ }^{-2}$.

Fig. 2 presents the kinetics of bainitic formation obtained by dilatometry. The time origin is set at the beginning of the $460^{\circ} \mathrm{C}$ isotherm. Table 1 summarizes the results by displaying the times needed to transform half of austenite into bainite. Fig. 2a shows the transformation of boron-free steel for three different grain sizes. No significant grain size effect is observed as all samples reached a $50 \%$ fraction 
of bainite transformed under $3 \mathrm{~s}$. The small disparities between samples can be ascribed to the dilatometer's limitations and the temperature oscillations after quenching to $460^{\circ} \mathrm{C}$.

Table 1. Time to reach $50 \%$ fraction of bainite for various austenite grain size and interfacial boron excess.

\begin{tabular}{lccccc} 
& & \multicolumn{4}{c}{ Boron excess } \\
\cline { 3 - 6 } & & 0 at.nm $^{-2}$ & 2.4 at.nm & 3.0 at.nm & 3.7 at.nm \\
\cline { 2 - 5 }$\gamma$ grain size & $2 \mu \mathrm{m}$ & $2.6 \mathrm{~s}$ & $46 \mathrm{~s}$ & - & - \\
& $12 \mu \mathrm{m}$ & $2.9 \mathrm{~s}$ & $42 \mathrm{~s}$ & $59 \mathrm{~s}$ & $102 \mathrm{~s}$ \\
& $50 \mu \mathrm{m}$ & $2.0 \mathrm{~s}$ & $10 \mathrm{~s}$ & - & - \\
\hline
\end{tabular}

Fig. $2 \mathrm{~b}$ shows the effect of boron excess on the isothermal bainitic transformation kinetics, for a constant grain size of $12 \mu \mathrm{m}$. Figs. $2 \mathrm{a}, 2 \mathrm{~b}$ and Table 1 show that the transformation kinetics is much faster for $0 \mathrm{~B}$ steel than for 30B steel. Addition of $30 \mathrm{ppm}$ B strongly inhibits the bainitic transformation. On one hand, for $0 \mathrm{~B}$ specimens, no incubation time is observed, and half transformation is completed under $3 \mathrm{~s}$. On the other hand, for 30B steel, the transformation occurs after an incubation time. Increasing the boron excess both delays and slows down the bainitic transformation. With boron excess increasing from 2.4 to 3.7 at.nm ${ }^{-2}$, the incubation time increases from $6 \mathrm{~s}$ to $19 \mathrm{~s}$, the time needed to reach $50 \%$ bainite is more than doubled, and the final transformed fraction after $180 \mathrm{~s}$ decreases from about $90 \%$ to $66 \%$.

Fig. 2c shows the effect of austenitic grain size for a constant boron excess of 2.4 at.nm ${ }^{-2}$. We see that larger grain size accelerates the transformation. The sample with largest grain size $\mathrm{d}_{\gamma}=50 \mu \mathrm{m}$ reaches $50 \%$ transformation four to five times faster than smaller grain size samples. Between $12 \mu \mathrm{m}$ and $8 \mu \mathrm{m}$, this effect is still noticeable. This trend is opposite to the expected behavior and is due to the boron addition, as no significant effect of grain size is observed for the boron-free steel.

To investigate the nucleation and growth mechanisms of bainite, microstructural and EBSD observations were performed. Figs. $3 \mathrm{a}$ and $3 \mathrm{~b}$ show the optical micrograph and inverse pole figure (IPF) of the boron-free steel with $\mathrm{d}_{\gamma}=8 \mu \mathrm{m}$ after $180 \mathrm{~s}$ at $460^{\circ} \mathrm{C}$. As a comparison, Figs. $3 \mathrm{c}$ and $3 \mathrm{~d}$ show the micrograph and IPF over the same area of the boron-added steel with $\mathrm{d}_{\gamma}=8$ and $\Gamma=2.4 \mathrm{at}^{\mathrm{nm}}{ }^{-2}$. In Figs. $3 \mathrm{a}$ and $3 \mathrm{c}$, martensite appears grey while bainite appears white with black carbides. In the bainitic phase, previous austenitic grains boundaries are revealed in black by the metabisulfite etching. The shapes drawn by etching are referred in this paper as "bainitic islands", an island corresponds to the laths of bainite transformed within the boundaries of a single prior austenite grain. On IPFs, black pixels represent boundaries between highly disoriented areas. We assume that they delimit bainite packets of closely oriented bainite laths. One bainitic island contains one or more packets. Martensite identified in Fig. 3c was manually hidden by a black mask in Fig. 3d.

Two different microstructures are observed. The 0B steel microstructure is almost fully bainitic with small fraction of film-shaped martensite (Fig. 3a), prior austenitic grain boundaries can hardly be discerned nor inferred from the pictures. However, IPF in Fig. $3 \mathrm{~b}$ shows an important number of few microns wide, lath-shaped bainitic packets. This indicates that every austenitic grain has been transformed into several bainite packets. These features are similar to those described in other works $[15,21] .30 \mathrm{~B}$ microstructure differs from $0 \mathrm{~B}$, only $75 \%$ of the microstructure is transformed into bainite (Fig. 3c). Almost completely transformed austenite grains are observed (red circles) while nearly no nucleation occurred in others (martensite, grey areas). The IPF in Fig. 3d reveals few bainite packets per bainite island. They are larger than in $0 \mathrm{~B}$ steel. In circle 1, about ten of them are observed inside a prior austenitic grain, while in circle 2, three grains were transformed into a fewer number of packets. It can be assumed that each packet originates from a single nucleus on a $\gamma \mathrm{GB}$. The differences in the number, size and shape of packets in Figs. $3 \mathrm{~b}$ and $3 \mathrm{~d}$ demonstrate that boron strongly decreases the number of bainite nuclei on $\gamma \mathrm{GB}$ during the isothermal transformation. 

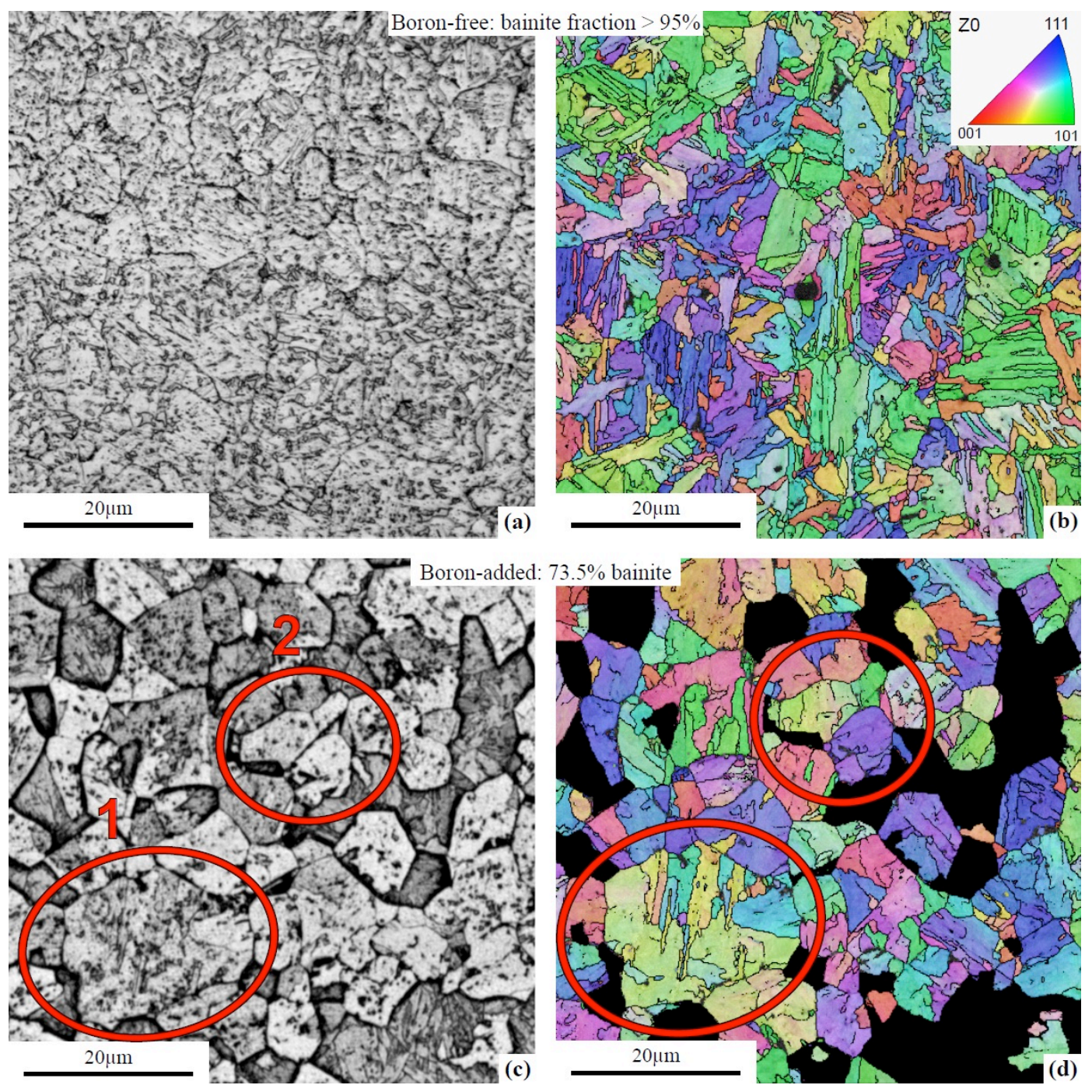

Figure 3. Optical micrographs and EBSD inverse pole figures after $180 \mathrm{~s}$ at $460^{\circ} \mathrm{C}$ of two samples with prior-austenite grain size $\mathrm{d}_{\gamma}=8 \mu \mathrm{m}$. a) and b) $0 \mathrm{~B}$ steel; c) and d) $30 \mathrm{~B}$ steel with $\Gamma=2.4$ at.nm ${ }^{-2}$.

Figs. 4a-d show the microstructure evolution during bainitic transformation of the $30 \mathrm{~B}$ steel with $\mathrm{d}_{\gamma}=8$ $\mu \mathrm{m}$ and $\Gamma=2.4 \mathrm{at}_{\mathrm{nm}}{ }^{-2}$. Optical microscopy does not provide the crystalline orientations. Therefore, bainite laths and packets can no longer be discerned inside each previous austenitic grain. However, as in Fig. 3c, grain-shaped bainite area can be discerned. They are delimited on micrographs by darker boundaries and bainite/martensite interfaces.

First nuclei appear between $10 \mathrm{~s}$ and $30 \mathrm{~s}$. Bainitic islands can be seen in partially transformed austenite grains (Fig. 4c). Fully transformed grains are already observed after $30 \mathrm{~s}$ (red arrows), while no nucleation has occurred in most austenite grains. In Fig. 4d, after $180 \mathrm{~s}$, bainite fraction reaches $74 \%$ but some austenite grains remain completely untransformed as no nucleation occurred on their boundary. Fig. $4 \mathrm{e}$ presents the size distribution of prior $\gamma$ grains (Fig. 4a) and bainitic islands (individually transformed $\gamma$ grain, Figs. 4c-d). The size frequency distributions of austenitic grains and bainitic islands after $30 \mathrm{~s}$ and $180 \mathrm{~s}$ are roughly similar. The mean bainite island size increases with the transformation advancement while it remains below the mean austenite grain size. The larger number of small bainitic islands $(<2 \mu \mathrm{m})$ after $30 \mathrm{~s}$ and $180 \mathrm{~s}$ is due to partially transformed austenitic grains. Fig 4 shows that the bainite islands (composed of one or more bainite packets) grow within their austenitic parent grain. For the transformation to progress, at least one nucleus must appear in every austenite grain. Figs. 3 and 
4 demonstrate that bainite nuclei form at a limited number of locations and that austenite grains are individually transformed into a small number of bainite packets.
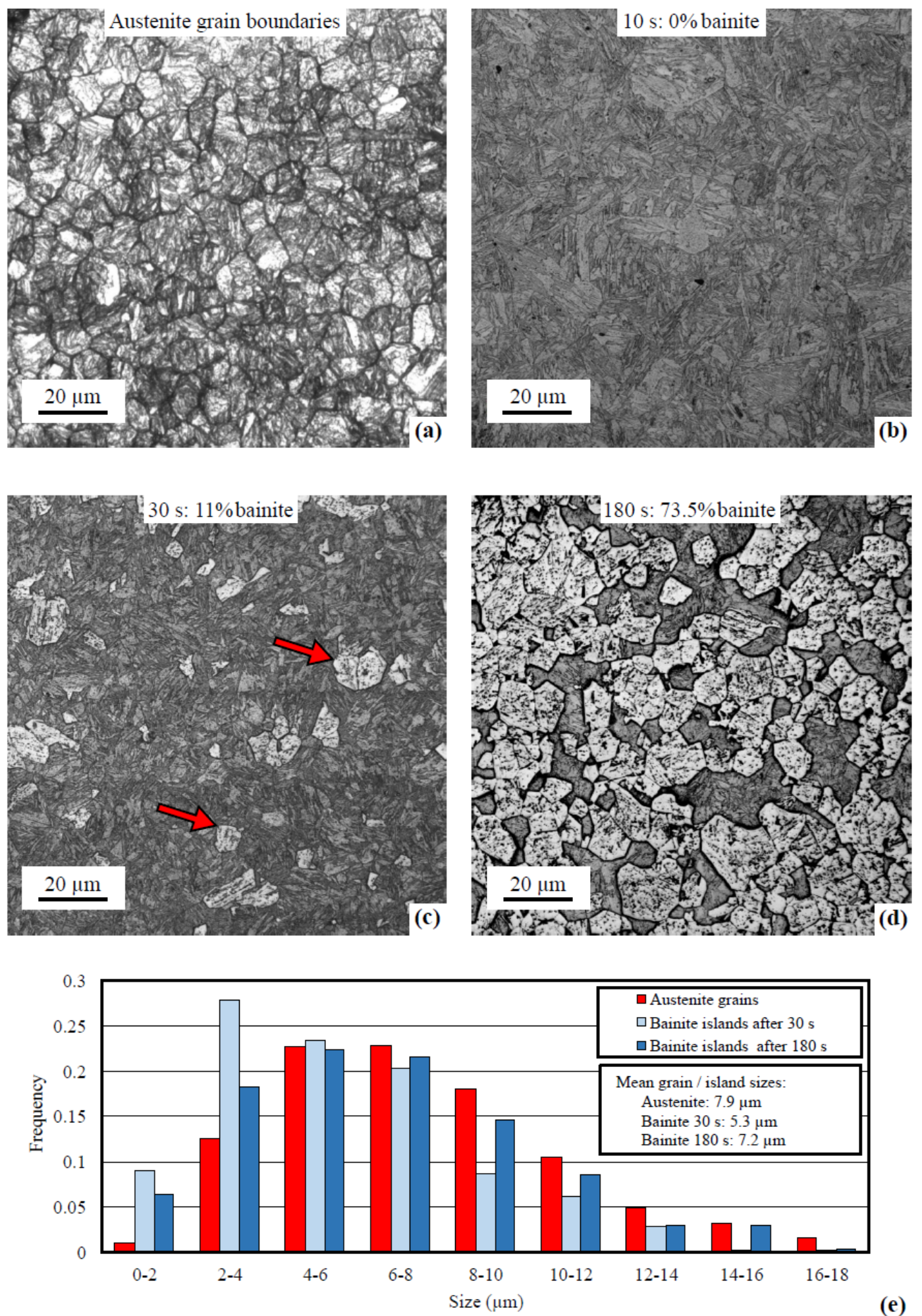

(e)

Figure 4. a)-d) Microstructural evolution during holding at $460^{\circ} \mathrm{C}$ of $30 \mathrm{~B}$ steel with prior-austenite grain size $\mathrm{d}_{\gamma}=8 \mu \mathrm{m}$ and $\Gamma=2.4 \mathrm{at.nm}^{-2}$. a) As quenched; b) $10 \mathrm{~s}$; c) $30 \mathrm{~s}$; d) $180 \mathrm{~s}$ holding; e) Austenite grain size and bainite island size distribution during $460^{\circ} \mathrm{C}$ isotherm (optical micrography cannot discern crystal orientations and packets). 
All these observations are in contradiction with the classical JMAK model which is often used to fit isothermal transformation kinetics. According to this model, the fraction of transformed phase is written $f=f_{\text {eq }}\left(1-\exp \left[-k t^{n}\right]\right)$, where parameters $k$ and $n$ depend on the nuclei geometry and location in the microstructure (grain boundary, grain edge or grain corner) and $f_{\text {eq }}$ is the equilibrium fraction [20]. Therefore, usual expressions of $k$ and $n$ lead to the consequence that smaller parent grains transform more rapidly than larger ones. This is not what we observed in our experiments: Fig. 2c shows that larger prior austenite grain size leads to faster transformation kinetics. For this reason, a model with alternate assumptions for nucleation and growth has been developed. Figs. 3 and 4 show that in most austenite grains, a bainitic island formed before any other nucleus could appear in the grain. In other words, an austenite grain transforms via a limited number of bainitic "bursts". According to that, we assumed that each nucleus rapidly forms a packet of volume $\beta V_{\gamma}$, where $1 / \beta$ is the average number of bainite packets per grain $(\beta<1)$ and $V_{\gamma}$ is the average volume of an austenite grain. With this hypothesis, the rate of extended fraction is proportional to the nucleation rate. If nucleation occurs at grain boundaries, we find, after some calculations, the transformation rate

$$
\frac{\mathrm{d} f^{e}}{\mathrm{~d} t}=I S_{\gamma}
$$

where $I$ is the nucleation rate (per unit time and unit area here) and $S_{\gamma}$ is the surface area of an austenite grain. Similar equations apply to nucleation on grain edges and on grain corners. We further assumed that the nucleation rate decreases with time as $I \propto \eta(\Gamma) t^{-n}, 0<n<1$. According to Gibbs' adsorption isotherm, boron segregation decreases the interfacial energy of the austenite grain boundaries, thus increasing the energy barrier for bainite nucleation. To take into account this retarding effect of boron segregation $\Gamma$ on the nucleation rate, we introduced the function $\eta(\Gamma)$ that decreases with increasing boron according to $\eta(\Gamma)=1-m \Gamma / \Gamma_{\max } \cdot \Gamma_{\max }$ is the boron excess at saturation and $m$ is a constant. Each type of nucleation site implies a different geometrical correlation between the site density $N$ and the average intercept $d_{\gamma}$ in the form $N \propto d_{\gamma}{ }^{p}$. Parameter $p=2$ for nucleation on grain boundaries, $p=1$ for edges and $p=0$ for corners. In the end, the extended transformed fraction as the general form

$$
f^{\mathrm{e}}=k \eta(\Gamma) d_{\gamma}^{p}[t-\tau(\Gamma)]^{1-n}
$$

where $k$ is a kinetic constant. To render the time lag observed in Fig. 2, we introduced a segregationdependent incubation time $\tau(\Gamma)$ as a linear function of $\Gamma$. The transformed fraction is $f=$ $f_{\text {eq }}\left(1-\exp \left[-f^{\mathrm{e}}\right]\right)$. The constant $f_{\mathrm{eq}}$ was set to the final bainite fraction.

An important parameter of the extended fraction Eq. (2) is the geometrical parameter $p$. For $p=0$, the transformation kinetics do not depend on grain size and so cannot fit our experimental data. Both $p=1$ and $p=2$ give a correct trend - i.e. larger grains accelerate the bainitic transformation - but the best fit was obtained for $p=1$, i.e. nucleation sites on edges (triple junctions). Fig. 2 displays the modelized kinetics with the adjusted parameters $n=0.1, m=4, f_{\text {eq }}=0.9$ and $k=7.2 \mathrm{~mm}^{-1} \cdot \mathrm{s}^{-1}$. Both boron excess effect and grain size effect are described rather accurately by the model.

Our finding that second-phase nucleation occurs on grain edges is not in agreement with some other works. Indeed, the assumption of nucleation on corner sites is often made to model ferritic transformation kinetics. Based on this hypothesis, Yoshida et al. obtained a good consistency between their experimental results and model [9]. The main reason for these conflicting outcomes is related to the transformation temperature: most works modelled the transformation in the ferritic temperature range while the present model applies to the bainitic temperature range. Both modelizations lack experimental evidence. A future more in-depth study of bainite nucleation sites by tomographic technics would be an interesting addition to this subject.

Boron does not impact the bainite growth and only affects its nucleation at austenite grain boundaries. So, one could expect that boron only impacts the beginning of transformation. After a while, the bainite 
volume fraction should reach a similar fraction regardless of boron addition. However, the experimental and modeling results show that boron segregation slows down the bainite transformation kinetics throughout the entire isotherm (Fig. 2b) in the range of our experiments (times up to $600 \mathrm{~s}$ at $460{ }^{\circ} \mathrm{C}$ ). This means that boron segregation inhibited bainite nucleation even after $180 \mathrm{~s}$ of holding (see Fig. 3c).

These results have important practical consequences for controlling the microstructure of low-carbon steels during overaging. First, the phase distribution: with boron, granular-like microstructure is obtained at $460^{\circ} \mathrm{C}$, with some prior austenite grains transformed into martensite and others fully transformed into bainite with small and granular-like bainite islands (different from granular bainite formed at $500^{\circ} \mathrm{C}$, but presenting similar bainite packets); without boron, a lath type microstructure (lathshaped bainitic packets surrounded by martensite films) is favored. Second consequence, the phase fractions: an optimization of boron segregation (via the control of grain size, soaking temperature, Mo and $\mathrm{Nb}$ additions $[6,7])$ could produce higher fractions of martensite after annealing.

To conclude, the effect of boron on the isothermal bainitic transformation was studied. By independently controlling the boron excess at austenite grain boundaries and the austenite grain size, we showed that boron segregation affects the kinetics of bainite transformation by inhibiting bainite nucleation at austenite grain boundaries. As a result, austenite transforms from a small number of bainite nuclei located at austenite grain edges. The increase of boron interfacial excess slows down the kinetics of isothermal bainitic transformation. Restricting the austenite grain size to less than $12 \mu \mathrm{m}$ greatly enhances the retarding effect of boron. The hypothesis of inhibited nucleation is confirmed by our model.

\section{Acknowledgements}

This project was supported by the National Association of Research and Technology, France (ANRT Project $n^{\circ} 2019 / 0700$ )

\section{References}

[1] G.F. Melloy , P.R. Summon, P.P. Podgursky, Metallurgical Transactions 4 (1973) 2279.

[2] X.L. He, Y.Y. Chu, J.J. Jonas, Acta metal. 37 (1989) 147-161.

[3] M. Ueno, K. Itoh, Tetsu-to-Hagané 74 (1988) 910-917.

[4] M. Ueno, T. Inoue, Transactions ISIJ 13 (1973) 210.

[5] K. Yamanaka, Y. Ohmori, Transactions ISIJ 17 (1977) 92.

[6] H Asahi, ISIJ International 42 (2002) 1150-1155.

[7] T. Hara, H. Asahi, R. Uemori , H. Tamehiro, ISIJ Int. 44 (2004) 1431-1440.

[8] J.E. Morral, T.B. Cameron, Metallurgical Transactions A 8 (1977) 1817.

[9] S. Yoshida, K. Ushioda, J. Ågren, ISIJ International 54 (2014) 685-692.

[10] H. Tamehiro, M. Murata, R. Habu, M. Nagumo, Transactions ISIJ 27 (1987) 120.

[11] C. Mesplont, S. Vandeputte, B. De Cooman, Zeitschrift für Metallkunde 93 (2002) 1108.

[12] X. M. Wang and X. L. He, ISIJ International Supplement 42 (2002) S38-S46.

[13] S. Khare, K. Lee, H.K.D.H. Bhadeshia, Int. J. Mater. Res. 100 (2009) 1513-1520. 
[14] K. Zhu, C. Oberbillig, C. Musik, D. Loison, T. Iung, Materials Science and Engineering A 528 (2011) 4222-4231.

[15] T. Song, B.C. De Cooman, Metall. Mater. Trans. A 44 (2013) 1686-1705.

[16] SJ Lee, JS Park, YK Leeb, Scripta Materialia 59 (2008) 87-90.

[17] L. Y. Lan, C. L. Qiu, D. W. Zhao, X. H. Gao and L. X. Du, Mater. Sci. Technol. 27 (2011) 1657.

[18] A.N. Kolmogorov, Bull. Acad. Sci. USSR. Ser. Math. 3 (1937) 355-359.

[19] M. Avrami, J. Chem. Phys. 8 (1940) 212-224.

[20] J.W. Christian, The Theory of Transformations in Metals and Alloys, third ed., Pergamon, Oxford, 2002.

[21] A. Matsuzaki and H. K. D. H. Bhadeshia, Mater Sci Tech 15 (1999) 518-522.

[22] Y. Shen, S.S. Hansen, Metall. Mater. Trans. A 28 (1997) 2027.

[23] Y.J. Li, D. Ponge, P. Choi, D. Raabe, Ultramicroscopy 159 (2015) 240-247.

[24] G. Da Rosa, P. Maugis, A. Portavoce, J. Drillet, N. Valle, E. Lentzen, K. Hoummada, Acta Materialia 182 (2020) 226-234.

[25] J. Takahashi, K. Ishikawa, K. Kawakami, M. Fujioka, N. Kubota, Acta Mater. 133 (2017) 41-54.

[26] P. Maugis, K. Hoummada, Scripta Materialia 120 (2016) 90-93.

[27] G. Da Rosa, PhD thesis, Aix-Marseille University, 2018. 